\section{Development of a New Cone- Beam Computed Tomography Software for Endodontic Diagnosis}

\author{
Mike R. Bueno ${ }^{1,2}$, Carlos Estrela ${ }^{3}$, Brunno C. Azevedo ${ }^{4}$, Anibal Diogenes ${ }^{5}$
}

'Department of Radiology, School of Dentistry São Leopoldo Mandic, Campinas, SP, Brazil ${ }^{2}$ CROIF, Cuiabá, MT, Brazil ${ }^{3}$ Department of Stomatologic Sciences, UFG - Universidade Federal de Goiás, Goiânia, G0, Brazil ${ }^{4}$ Department of Radiology, School of Dentistry, University of Louisville, Louisville, TX, USA ${ }^{5}$ Department of Endodontics, University of Texas Health at San Antonio, TX, USA

Correspondence: Prof. Dr. Carlos Estrela, Setor Universitário, 74605-220 Goiânia, GO, Brazil. Tel. +55-62-32096254. e-mail: estrela3@terra.com.br

Key Words: Artifacts, cone-beam computed tomography, diagnosis, root canal treatment, software.

\section{Introduction}

The challenges of making a diagnosis after the acquisition and interpretation of complex dentomaxillofacial structures images have led to important advances in Endodontics. The introduction of cone-beam computer tomography in Endodontics (1-4) has provided unprecedented information that greatly aids diagnosis and treatment planning (510), as well as providing three-dimensional guidance during root canal treatment. Importantly, CBCT has had a dramatic effect in endodontics since it has changed the way outcomes are assessed, and therefore have become an integral part of the evaluation of whether treatment protocols should be maintained or adjusted (11).

Cone-beam computed tomography (CBCT) offers multi-plane dynamic navigation, data correction by adjusting brightness and contrast and adjustment of volume parameters such as slice-thickness and slice interval $(9,10,12,13)$. Because of its higher specificity and sensitivity in relationship to hard tissue pathoses when compared to 2D imaging, this imaging technique may be used for multiple clinical applications and research. CBCT has brought clinical benefits to almost all areas of dentistry: Endodontics, Surgery, Implantology, Orthodontics, Periodontics, temporomandibular disorders and diagnostic imaging (5-9). Comparisons with periapical and panoramic radiography (14-16), whose limitations are well known (14,15,17-21), revealed that the use of CBCT in Endodontics increases the precision of diagnoses of apical periodontitis and inflammatory root resorption. A wealth of data is available for diagnosis and treatment plan, and, consequently, treatment results are more predictable $(5-8,11,17)$. The elimination of overlapping anatomy in different planes (coronal, axial, sagittal, oblique) and its high resolution and contrast differentiate this imaging technique from others. CBCT scanning has been recommended for different purposes, such as evaluation of root canal anatomy, assessment of developmental anomalies, root canal preparation, root fillings, retreatment, detection of periapical lesions, periapical surgery, traumatic dental injuries (root resorptions) (5-10) and research in Endodontics (5-16). Lastly, the use of a map-reading approach with CBCT images may minimize various problems associated with 
difficult assessment conditions, such as complex, unclear cases that require special attention during diagnosis (17).

Therefore, in contemporary Endodontics, technological innovations supported by three-dimensional CBCT studies have established a true revolution, which has naturally led to the need to review some structured concepts based on conventional imaging methods. However, the speed of changes and the amount of information that is offered daily to clinicians require permanent updating and incorporation of effective knowledge, so that health professionals can make better use of the resources offered by these new technologies. Despite the many advantages brought by CBCT incorporation in Endodontics, there are still many challenges to be overcome. Some of these challenges are currently not addressed by existing viewing software. Therefore, this study reviews the potential of a novel CBCT viewing software (e-vol DX) that supports diagnosing, planning and managing the treatment of complex endodontic cases.

\section{Cone-Beam Computed Tomography}

Computed tomography is an imaging technique that provides multi-plane visualization of scanned anatomical its image quality is better, as it differentiates specific structures, such as enamel, dentin, pulp cavity and alveolar cortical bone $(9,10,12,13,22-28)$.

Image acquisition using cone-beam is very technique sensitive, and, therefore, the patient's head must remain motionless during image acquisition to avoid motion artifacts which can degrade image quality. The C-arm containing the imaging sensor and the $\mathrm{x}$-ray tube rotates around the patient and acquires multiple two-dimensional images called base images in different projections. Adesktop computer performs a primary volume reconstruction $(5,9,12,22-24,26-33)$.

After the volume is reconstructed data should be corrected for orientation and optimized for display by adjusting brightness and contract. In addition, CBCT volumes can be reconstructed into others threedimensional views, such as panoramic reconstructions and volume rendering $(5,8-10,12,22-24,31-33)$. Various factors may interfere with the final result of the image quality: 1) Area sensor type, air gap (space between X-ray emitter and sensor), patient stabilization system (patient immobilizer), CT scanner column stability, voxel size, field of view (FOV), tube head focal point size, volume noise, dynamic image range, $\mathrm{X}$-ray parameters kilovoltage and milliamperage, native acquisition software, scanner calibration; 2) patient - density of complex craniofacial structures, patient stability, patient position, amount and density of materials in the patient's mouth; 3) software - general software design, image editing design, dynamic image range, sharpness of noise and margin size controls, artifact reduction, functional 3D (multi-way browser), multidirectional browser, compression with or without lost data logging, oblique coordinate logging, registration of filter settings for replication, specific search tools and images in the Digital Imaging and Communications in Medicine (DICOM) format (34).

As in conventional medical CT, CBCT systems can export images as DICOM. DICOM stands for Digital Imaging and Communications in Medicine. Specification for messaging and communication between imaging machines can be integrated and visualized in a single digital filing system that can be opened using a specific software application. This file can store technical acquisition data, date and patient clinical information, and may be converted to an STL format to obtain three-dimensional models $(8,9,30)$.

CBCT scanners have their own characteristics and differ in sensor type, field of view (FOV), resolution and software. These differences make certain devices more suitable for uses in which a high-resolution image is necessary, differing from other cases in which a greater volume area is required (3133). Thus, it is possible to classify CBCT scanners according to size and FOV: small volume devices; large volume appliances; large and small volume apparatus $(5,8-10,12,22-29)$. In addition to the proprietary viewing software that is native to each CBCT scanner, images can be exported as DICOM images and be viewed and manipulated in third party software. DICOM images can be segmented and uploaded to a 3D printer to generate physical models, which are accurate, tactile and three-dimensional representations of the patient's anatomy. These models may be used especially in cases involving complex planning approaches (8). Lastly, advancements in hardware and software developments have allowed for reduced radiation needed for, good quality, acceptable diagnostic scans. Indeed, the radiation dose from a CBCT exam is slightly higher than that of periapical radiography, but much lower than that of conventional CT scans. The exact dose of radiation depends on some characteristics of the examination and of the scanner, such as kilovoltage and milliamperage, scanner model, scanned area $(9,10,26,35-37)$.

\section{A Novel CBCT Software}

Different manufacturers have developed several CBCT devices, each one accompanied by its specific software. The need for high quality images, visualization of complex anatomical structures, precise identification of occult 
lesions (possibly undetected) and reduction of artifacts led CDT Software (Bauru, SP, Brazil) to develop the e-Vol DX software. A particular feature of this CBCT software is the ability to import, work with DICOM files, and standardize image adjustments to analyze CBCT volumes from different sources.

\section{Main Features of the e-Vol DX Software}

Original CBCT images may not be well-suited for viewing. They may be blurred, not sharp enough and might contain numerous artifacts. These images require a series of adjustments to improve image quality. Thus, this novel CBCT software has been developed with important features to improve image quality, which include task specific brightness and contrast adjustment, custom image thickness control, custom image sharpening filter, a proprietary noise reduction filter and the capability to automatically recognize data from different $\mathrm{CBCT}$ scanners and apply scanner specific which results in saving time during imaging navigation and high-resolution image capture. All these tools, together with especially developed $3 \mathrm{D}$ rendering filters, reduce artifacts that may negatively affect the establishment of precise diagnoses.

\section{Brightness and Contrast Setting}

The e-Vol DX software preserves all the dynamic range of DICOM files. Thus, adjustments can also be applied to the lighter and darker areas of the image, with wide latitude. Most other software applications do not work with all the dynamic range of DICOM files because their adjustments are usually limited and narrow in nature, which result in the sub-utilization of already acquired data that is not fully exploited to overcome the above-mentioned challenges.

\section{Slice Thickness and Noise Reduction}

The slice thickness is inversely proportional to image noise. Unfortunately, most viewing software have predefined slide thickness without proper correction for noise. As result, increased slice thickness may have to be used simply to primarily to control image noise. However, fine structures may be easily missed when greater thickness slices are used. The e-vol DX software has unique noise filters that allow endodontists to determine task specific slice thickness by freely adjusting this setting without major loss of image quality. Therefore, the high quality of the imaging exam can be preserved, and the thickness can be reduced without degradation of the image.

Sharpness adjustment

This software has an advanced filter to increase sharpness that uses two complementary and combined sharp adjustments: in Sharp 1, the filter is graduated into 100 levels; in filter 2, radius is controlled separately from slice thickness margin, also using a graduated scale of 100 levels. To date, this level of adjustment has not been available since this adjustment is usually very limited, usually containing only 5 to 8 levels, and with no second margin control filter.

\section{Image Capture in High Resolution}

This novel CBCT software captures images at a resolution of $192 \mathrm{dpi}$, with an option for $384 \mathrm{dpi}$. Most CBCT applications capture images at $96 \mathrm{dpi}$. As images are captured by area, images captured using this CBCT application have 4 to 16 times more pixels than those captured by applications that use $96 \mathrm{dpi}$. This results in greater image quality and improves zoomed-in images used in studies that include captured images, images for print publications and enlarged images in digital publications.

\section{Clinical Uses of this Novel CBCT Software Application}

This CBCT software application supports decisionmaking, diagnosing and treatment impact in Endodontics because it produces high-resolution images by using DICOM files from different sources. Some clinical cases are described below to illustrate its potential uses and its important contributions.

A reduced potential of image contrast artifacts resulting from the accumulation of white tone has a substantial impact on the quality of information, which may be misinterpreted. Clinical case 1 (Fig. 1) describes CBCT images of teeth \#11 and \#21 that have white contrast artifacts (blown highlights), which make it difficult to identify the failed root canal treatment. In the e-Vol DX CBCT images, the filter was used, and the normal contrast of the gray scale image was preserved. This filter reduces the white areas of the original image. Therefore, the filling material inside the root canal does not produce artifacts, and even the number of gutta-percha points can be counted.

White contrast artifacts (blown highlights) on a CBCT scan may hide a fracture, as well as a lateral rarefaction, and lead to image misinterpretations. Clinical case 2 (Fig. 2) shows the CBCT report produced by e-Vol DX. In the CBCT images showing tooth \#21, a white contrast artifact (blown highlights) prevents the visualization of a vertical root fracture and hides a lateral rarefaction. After utilizing built-in filters in the e-vol DX software, gray scale contrast can be corrected, clear areas are reduced, and palatal vertical radicular fracture may be identified more easily. Using other filters, images produced by this software can be reconstructed according to the characteristics of the dental structure. In addition, anatomical details can be identified, as lateral canals at higher magnifications without image deformation, and all root surfaces can be navigated.

The e-Vol DX CBCT report of clinical case 3 (Fig. 3) reveals 
a lateral canal in tooth \#37. The anatomical details of this inner lateral canal and its external surface (periodontal ligament) may be seen clearly, using this new technology, at higher magnifications that preserve the resolution and unique anatomy of fine and small structures. This filter also facilitates the visualization of the root canal position and its distance from the furcation or periodontal ligament, and accurately establishes the existence of a mesial middle root canal when compared with very clear CBCT images on axial slices.

Another interesting filter transforms CBCT images into transparent mode images. Clinical case 4 (Fig. 4) shows a transparent image of tooth \#26. Specific details of the coronal chamber, as well as volume and adjacent structures, are clearly visualized. This direct visualization of the 3D model allows for excellent treatment planning and provides immediate clinically applicable information, since the clinician is not studying 2 dimensional images from the
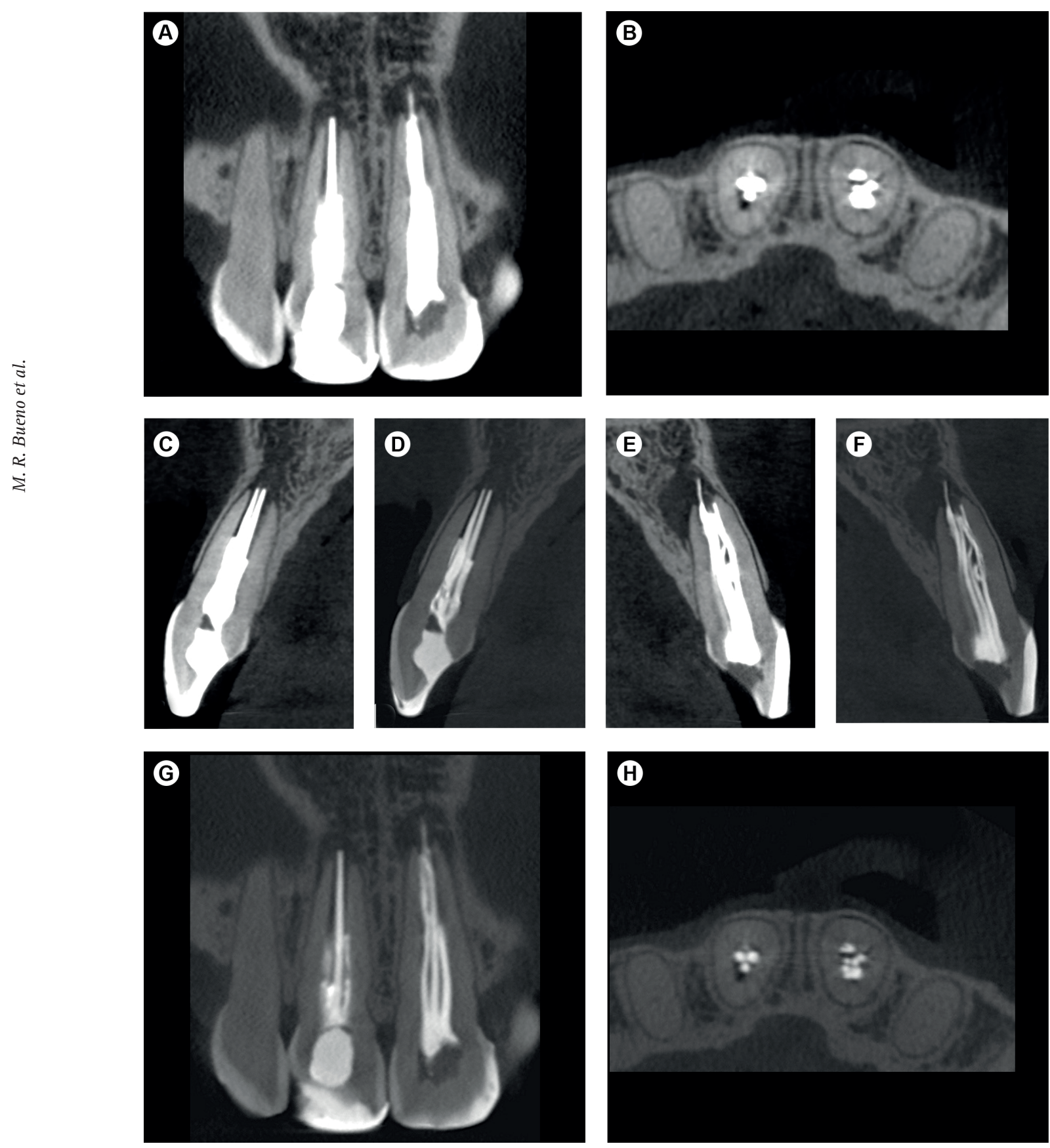

Figure 1. $(A-B)$ CBCT report produced by e-Vol DX shows the teeth \# 11 and 21 with white contrast artifacts, which make it difficult to identify the failed root canal treatment; $(C-H)$ in the e-Vol DX CBCT images, the filter was used and the contrast of the grayscale was preserved, which reduces the white areas of the original image. 
3 axis (coronal, sagittal and axial) and later "envisioning" a 3D structure mentally. Instead, the e-Vol DX produces 3 dimensional renders that can be immediately interpreted revealing unique internal structures of the tooth and its surrounding tissues, thus providing valuable information that assists in all steps of endodontic treatment.

Further, detailed information about previously treated root canals, and especially areas of osteolysis, may be better visualized using filters in this software that were designed to highlight these structures. Clinical case 5 (Fig. 5) illustrates this capability as demonstrated with the color alternation of the filling material in tooth \#36, improving the visualization of apical extent of the root filling and assessment of root canal volume. It may also provide information about the absence or presence of periapical osteolysis.

The precise apical foramen position may be defined using a specific image reconstruction filter in the e-Vol. The cursor for navigation dynamics may be used as a guide
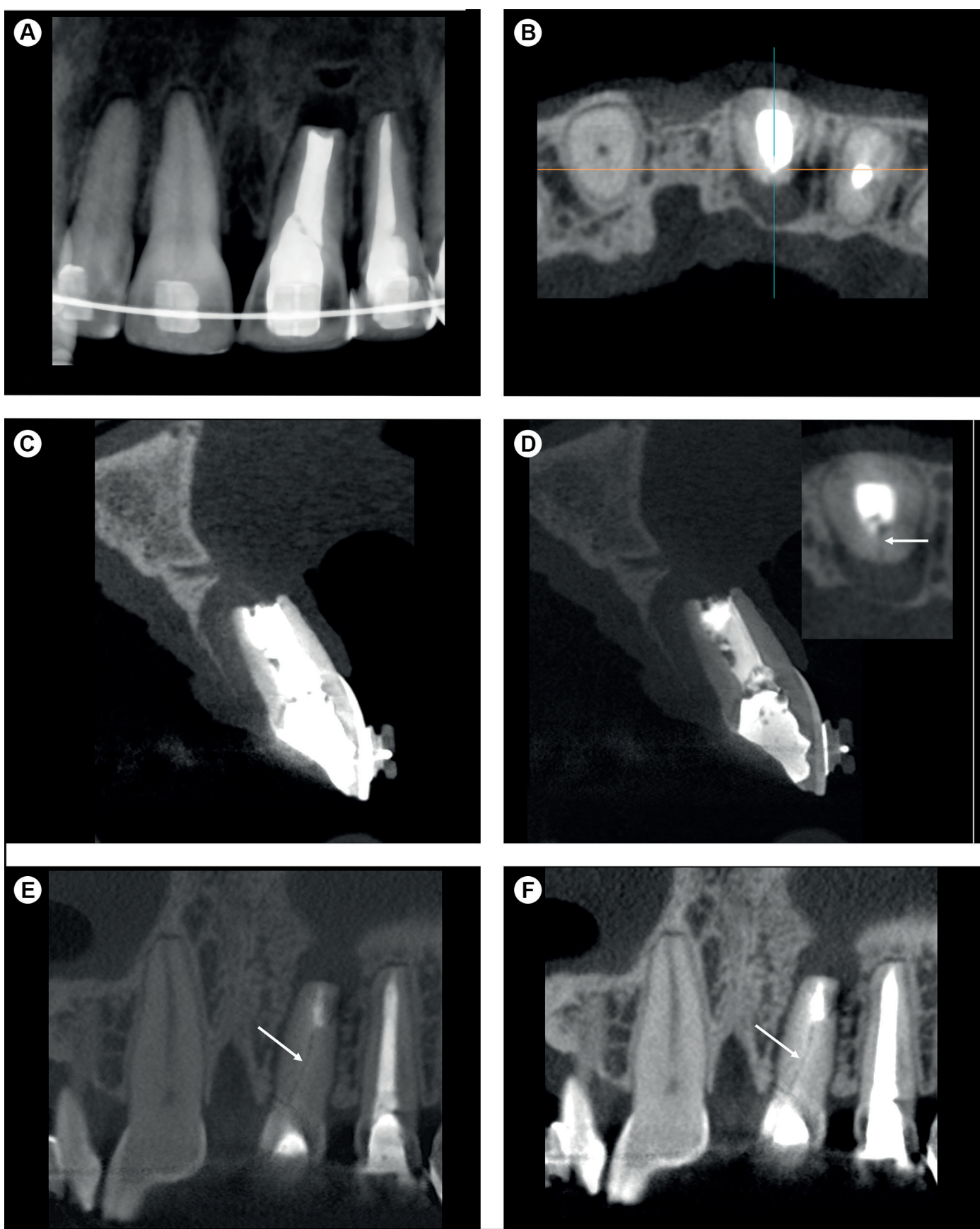

Figure 2. $(A-B)$ e-Vol DX CBCT images showing tooth \# 21 with white contrast artifact prevents the visualization of a vertical root fracture and hides a lateral rarefaction; (C-F) In CBCT images produced with a filter for normal contrast of the grayscale, clear areas are reduced, and palatal vertical radicular fracture may be identified more easily. 
and an important anatomical reference. In clinical case 6 (Fig. 6), the e-Vol DX CBCT report shows the shape and position of the apical foramen of tooth \# 35 after the use of a reconstruction filter. The cursor may be placed in the transparent root canal to reach the apical foramen, and several other aspects may be analyzed, such as area and volume before and after canal cleaning and shaping, filling and wear after retreatment. Area volume can be calculated using specific tools of this novel software. Other aspects, such as the internal geometry of the root canal, may be identified when filters are used in alternation. The e-Vol DX CBCT images may show the middle mesial root canal of tooth \#36 easily viewed with a specific reconstruction filter (Fig. 7).

\section{Discussion}

CBCT, a notable technological advancement, has been fully incorporated in Endodontics. The impact of this imaging technique on diagnoses, treatment planning and decision-making has translated into clinical benefits and
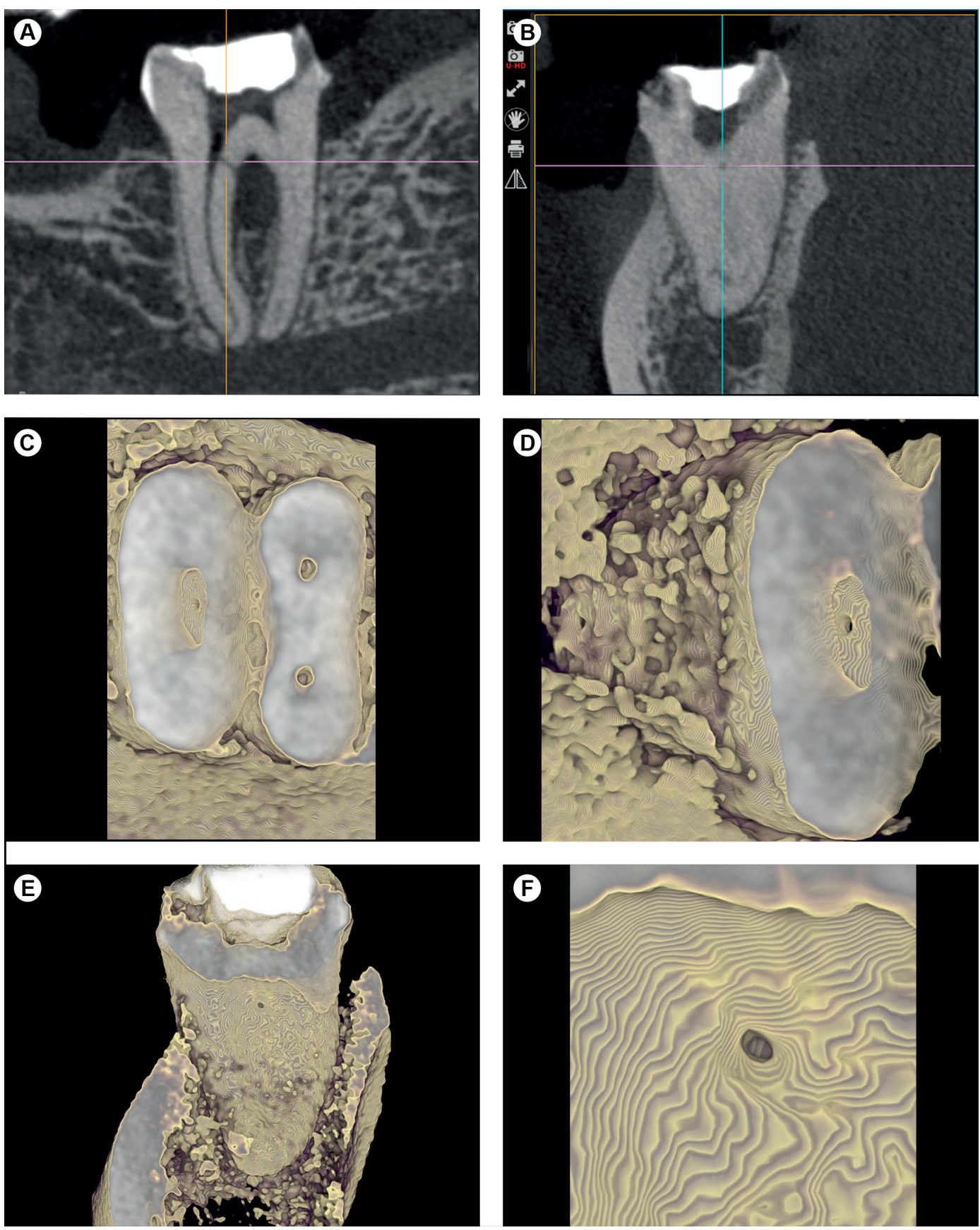

Figure 3. $(A-B)$ The e-Vol DX CBCT images reveals a lateral canal in tooth \# 37; $(C-F)$ The filter favor the visualization of anatomical details of this inner lateral canal and its external surface (periodontal ligament) may be seen clearly at higher magnifications. 
greater treatment quality and efficacy.

The development of the e-Vol DX application has been a response to the unmet need for software that preserved all the dynamic range of DICOM files, as it analyzes DICOM files from different CT scanners and produces images with normal contrast. Its filters have been developed to reduce artifacts and show the shades of gray that best characterize the actual structure of the object on the image.

The principle of image capture in a photography camera is essential to understand and use this software, as its image capture process essentially defines its final quality.
The RAW (native) image format consists of the database of the captured object and a large number of pixels of the sensor. Some filters developed for the e-Vol DX package have been adjusted to the principles of the RAW format, which preserves the quality of the acquired image and potentially recovers underexposed or overexposed areas. These filters avoid loss of image quality and improve the saturation and brightness of specific areas, because the light areas of the image occupy a substantial amount of file space. They also prevent loss of image quality by using either white burst (streaks) or gray color, which is usually
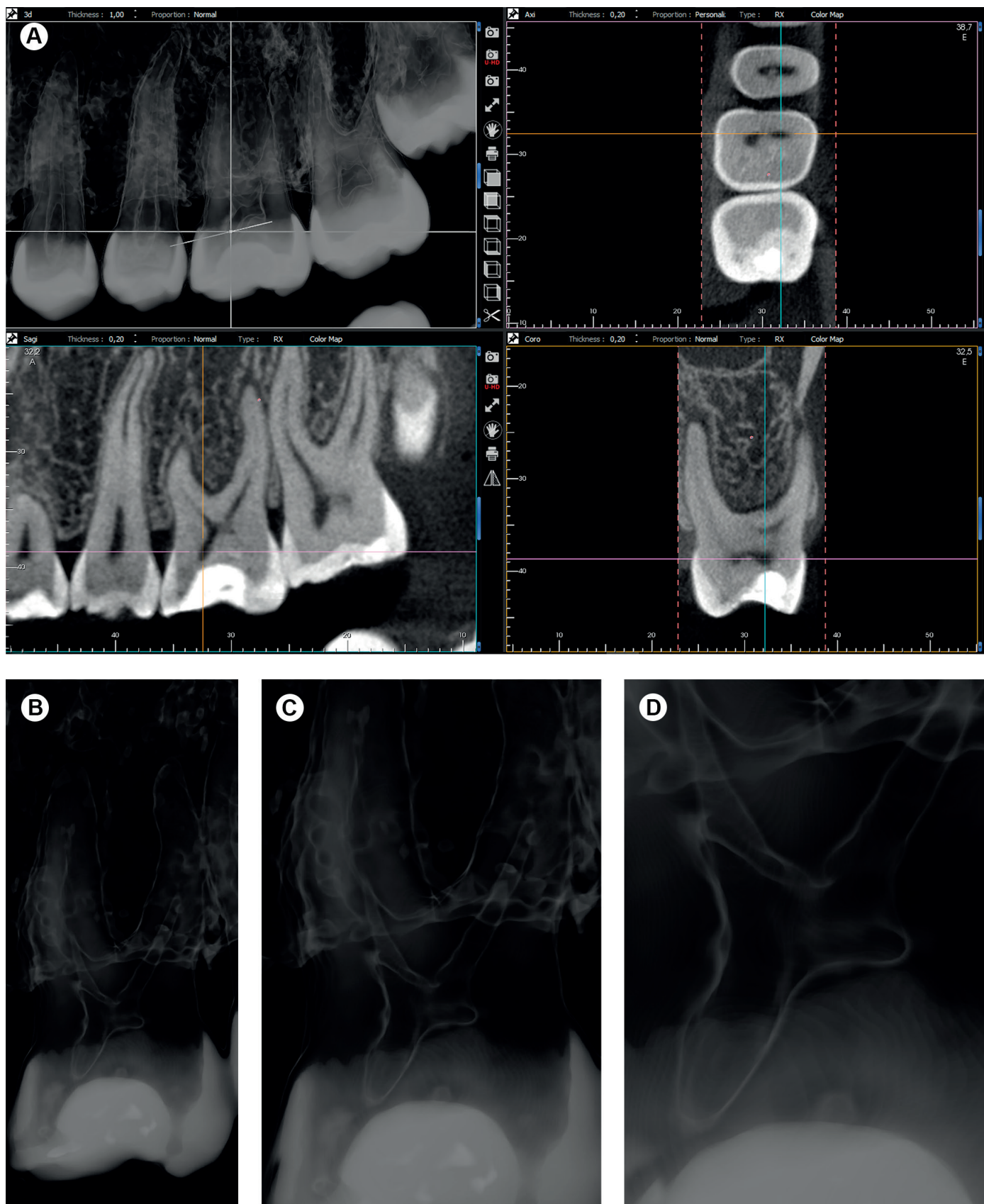

Figure 4. (A) Another filter transforms СBCT images into transparent mode images, such as showed in tooth \# 26; (B-D) Specific details of the coronal chamber, as well as volume and adjacent structures are clearly visualized. 
transformed into white color (34).

The principles of CBCT image formation for endodontic applications have deserved special attention, because artifacts may arise from high-density materials (such as root canal obturations, intrarradicular posts) and affect image quality and accurate identification of the structures to be analyzed. Technical knowledge of digital photography (38) and the fact that the clear area of an image occupies almost half of the file space are indications that the reduction of light or white area results in substantial reduction of artifacts.

Imaging diagnoses are defined by different parameters (34), and technical image quality settings, such as resolution of line pairs, modulation transfer change, grayscale range and amount of mottle and sharpness, are fundamental references for it (39). Pauwels et al. (40) presented an important explanation of the principles of cone-beam image acquisition and image reconstruction. They reported that
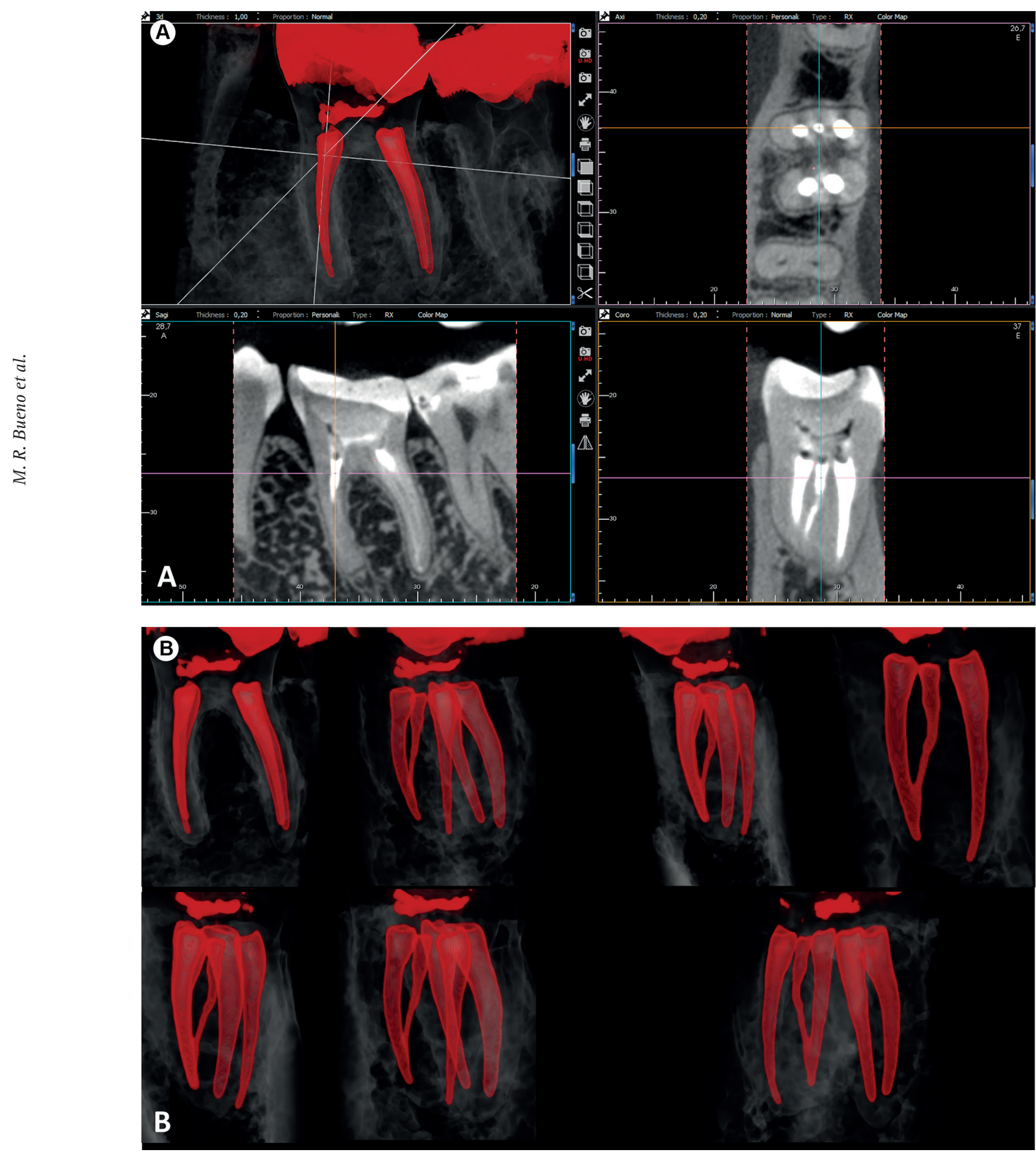

Figure 5. $(A-B)$ The e-Vol DX CBCT images showing tooth \#36 with detailed information about root canal obturation, and may also provide information about the absence or presence of periapical osteolysis. 
after reconstruction, $\mathrm{CBCT}$ images could be manipulated in different ways to optimize the visualization of anatomical structures and lesions. The most basic manipulation is performed to optimize contrast in the image, by displaying only part of the full grey value range. The full contrast of the display monitor, as well as the human eye, is applied to this particular grey value range. These operations may have different purposes: in dental $\mathrm{CBCT}$, they are mainly used to optimize the contrast in the bone density range, which corresponds to bone grey values (40).
The capture, processing and formation of 3D images follow important phases to obtain an image of good quality and prevent artifacts. Operative errors due to misinterpretations have negative impacts on planning, diagnosis and endodontic treatment (34). A good quality image should contain all the information obtained when the tissue (object) is radiographed and be sharp and accurate, without spaces that may induce infiltrations or overlapping layers. Distortions, such as beam hardening, cupping artifact, hypodense halo, streaks and volume
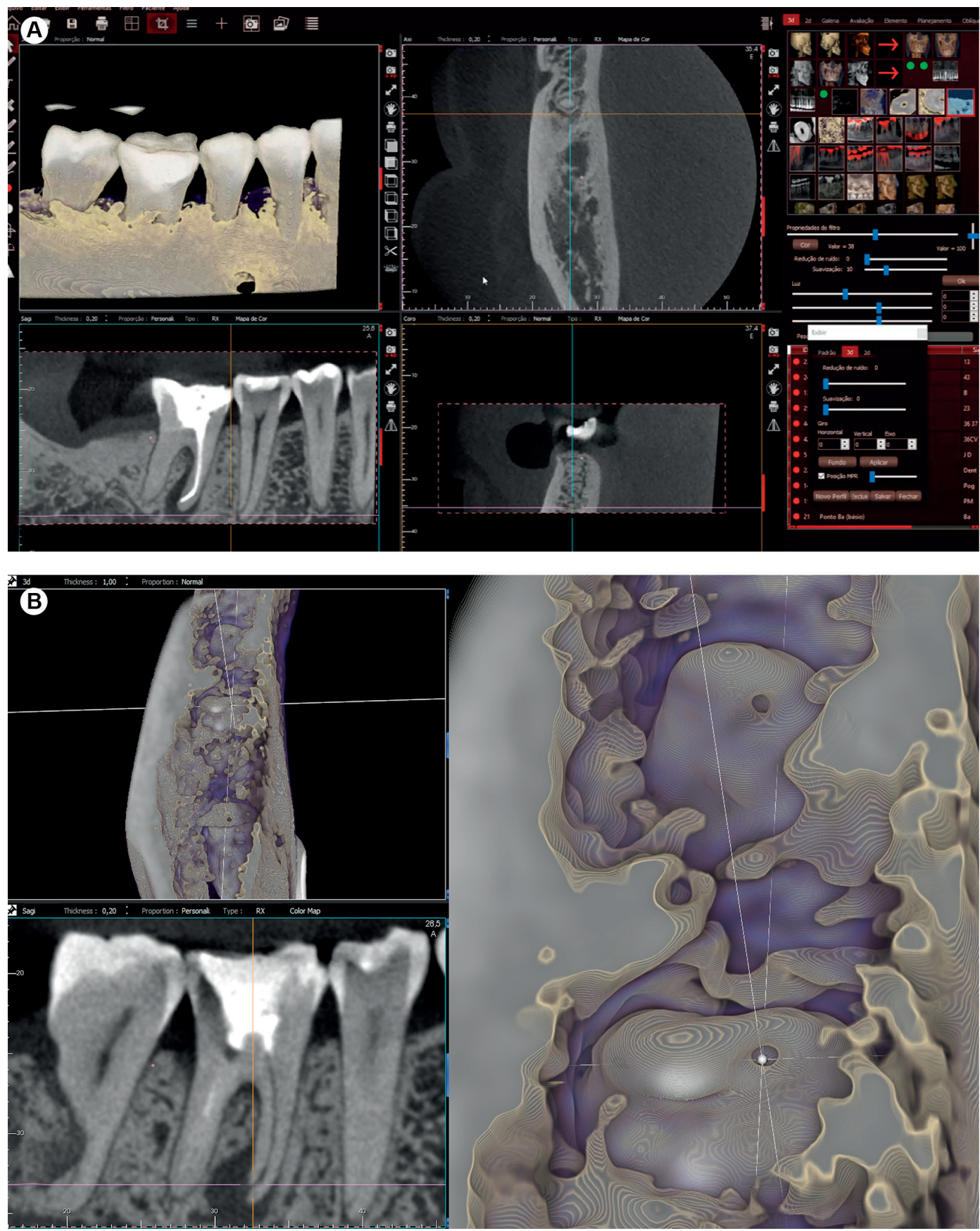

Figure 6. (A-B) The e-Vol DX CBCT images shows the shape and position of the apical foramen of tooth \#35. 
overestimation, may occur during the reconstruction of images of original objects (41). Reduction of the errors found on CBCT images of high-density structures or materials constitute a major challenge. One initial concern in endodontic practice is the presence of metallic artifacts produced by obturations or intracanal posts, which may limit interpretation and image quality and induce diagnostic errors (42-54).

Root canal filling measurements of the original root specimens and of CBCT images are discrepant, and root canal filling dimensions are greater on CBCT images than on the original root specimen, especially when a sealer was present. Root canal materials produce distinct degrees of image artifacts according to their material density (44). The increase of intracanal post dimensions on CBCT images of endodontically treated teeth was also found in specimens with gold and silver alloy posts, and findings were significantly different from those observed for glass fiber, carbon fiber and metal posts (45). Metal posts and voxel size are two factors that significantly interfere with the diagnosis of vertical root fractures (46). Although metal artifacts are associated with metallic cores, filter
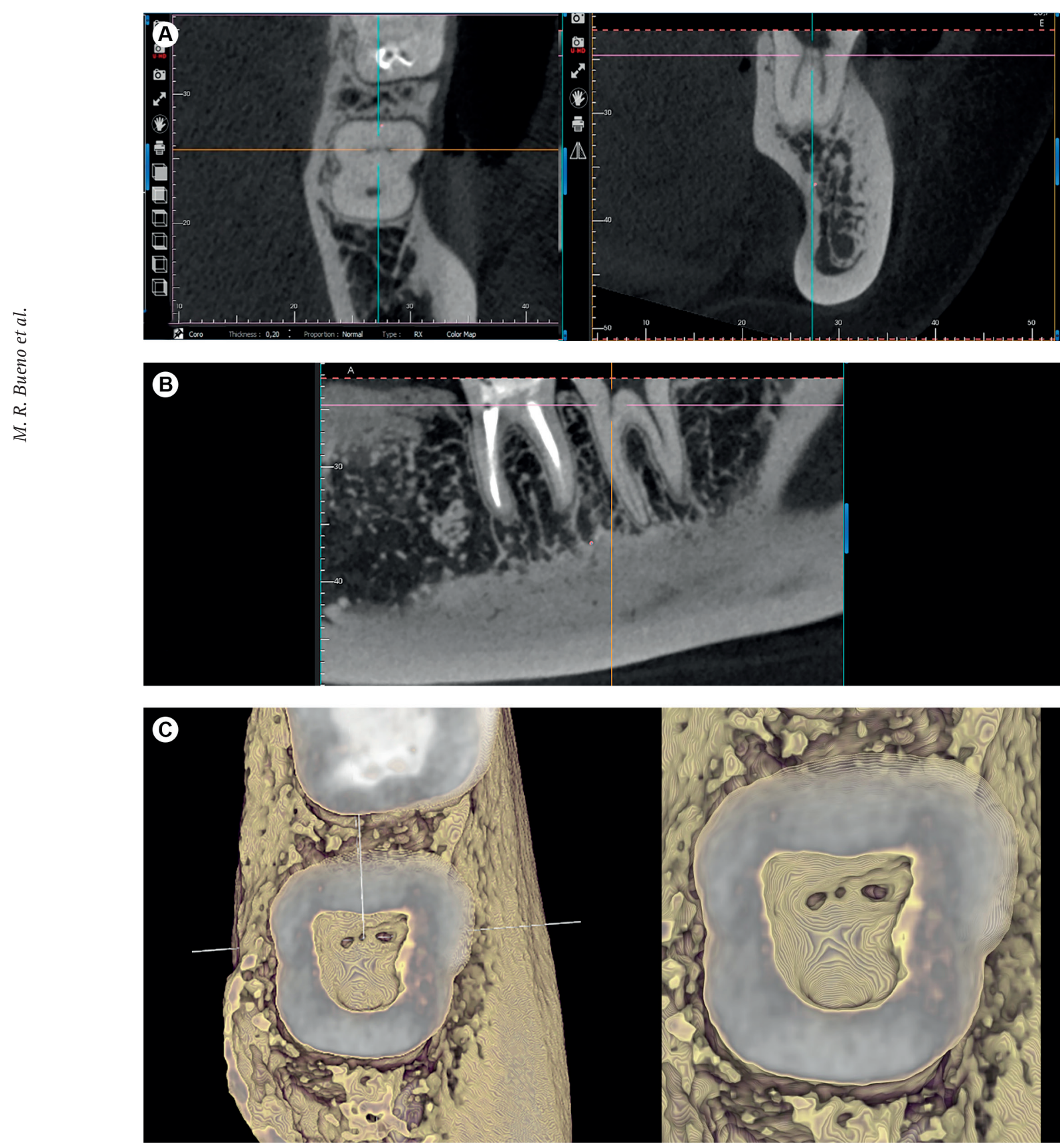

Figure 7. The e-Vol DX CBCT images $(A-C)$ shows the middle mesial root canal of tooth \# 36 easily viewed with a reconstruction filter. 
applications do not improve diagnoses. For mesiodistal vertical root fractures, CBCT is superior to periapical radiography (46). The comparison of the diagnostic value of six intraoral digital receptors and a CBCT scanning system for detection of voids in root fillings revealed that six intraoral receptors performed almost equally in the detection of voids in root fillings, and the extension of voids was underestimated by all systems (47). CBCT axial sections had a higher sensitivity, as more voids were detected, but at the same time voids might be overdiagnosed (falsepositive recordings) because of the artifacts produced by gutta-percha root fillings. Fox et al. (48) described a novel technique to characterize beam hardening $(\mathrm{BH})$ artifacts on CBCT images produced by three root canal filling materials and to evaluate the effects of a zirconium-based root filling material with a lower K edge ( $17.99 \mathrm{keV})$ on the production of $\mathrm{BH}$ artifacts. Root canal fillings with reduced $\mathrm{K}$ edge radiologic properties can reduce the impact of $\mathrm{BH}$ artifacts. A phantom tooth model used in conjunction with different root fillings accurately showed the characteristics of $\mathrm{BH}$ artifacts. The comparison of volume distortion artifacts of root canal sealers using $\mathrm{CBCT}$ devices and micro-CT imaging as a reference revealed that $\mathrm{CBCT}$ produced more volumetric distortion artifacts than micro-CT imaging. The volume was variable for different $\mathrm{CBCT}$ devices while scanning at the same voxel size (49). Other authors have studied software applications that make images sharper and do not interfere with the maxillofacial complex $(53,54)$.

The indication of CBCT examinations in endodontics should follow guidelines for its rational use because its radiation dose is higher than that of periapical radiography. The guidelines for the use of CBCT in Endodontics should follow the ALARA principle (55-59). Moreover, the specialists that interpret CBCT images should be carefully trained to evaluate these scans and qualified for the analysis of technical parameters that affect radiation doses, in agreement with the ALADA principle $(26,59)$. This novel software package, e-Vol DX, offers high image quality captured using protocols with less exposure time (a smaller number of base images) than those acquisition protocols that have greater exposure times and radiation doses. These aspects are important because imaging exams using $\mathrm{CBCT}$ have an impact on diagnosing and decisionmaking in clinical practice, and because their indication should follow the ALARA and ALADA principles $(26,55-59)$.

Numerous anatomical details, including ramifications, lateral canals, apical foramen, root canal isthmus and mesial middle root canals may be reconstructed if the characteristics of the dental structure are known, and they may be seen clearly and at greater magnifications using the e-Vol DX application.

Different filters and several tools have been developed for the e-Vol DX software, and they may be used in a variety of clinical endodontic settings (Figs. 1-7). The e-Vol DX potential for clinical applications and research (60) has been initially evaluated and illustrated in the clinical cases described in this study. An accurate analysis of the benefits of this novel CBCT software use and its applications will take some time before its use is incorporated into clinical practice. Nonetheless, advances in information technology in the field of knowledge and examination of images are promising. There is great potential to expand current knowledge about СBCT and its repercussions. Sharper images, more sophisticated software applications and an organized database of images should be based on these new developments, especially the observation of patterns and their deviations, in common with other areas of research (34).

Some future technological advances of CT scanners may include sharper images and greater enlargement, higher quality diagnostic tools, cleaner images, artifact reduction, mechanical movement stabilizer, reduction of radiation doses, as well as software applications for separation of subtle 3D shapes, transformation of forms into STL, CT superposition, volume measurement, 3D functionality, full dynamic scope of the DICOM format, sub-millimeter measurements, multidirectional image tracing, tracking curved images, oblique position recorder, position indexing including 3D, sharing information with dynamic files and cloud information sharing.

The application of this novel CBCT software is an important advancement, because it interprets DICOM files from different CT manufacturers and uses several filters that, together, may improve the predictability of an accurate diagnosis and, consequently, of a better clinical decision-making. Improved image quality favors the rational prescription and interpretation of $\mathrm{CBCT}$ scans and fully utilizes the data captured by the existing CBCT equipment regardless manufacturer and hardware design.

\section{Resumo}

A tomografia computadorizada de feixe cônico (TCFC) promoveu mudanças nas abordagens de Endodontia e melhorou a tomada de decisões em casos clínicos complexos. Apesar dos avanços tecnológicos no hardware da TCFC, a interpretação da imagem adquirida ainda é comprometida pela visualização dos softwares, que muitas vezes têm ferramentas de navegação limitadas e falta de filtros adequados para superar estes desafios, como artefatos. Este estudo analisa as limitações atuais da TCFC e o potencial de um novo software (e-Vol DX, CDT-Brasil) para superar estes aspectos e apoiar o diagnóstico, planejamento e monitoramento de casos endodônticos. Este método de imagem fornece imagens em alta resolução devido a tamanhos submilimétricos de voxel, navegação dinâmica de imagens em vários planos e capacidade de alterar os parâmetros de volume como espessura de corte, intervalos de corte, correção de dados por meio de filtros de imagem, e manipulação do brilho e do contraste. As principais diferencas entre o e-Vol DX e outros software são: compatibilidade com todos os scanners de TCFC atuais com capacidade de exportar dados DICOM, com ajuste de brilho e contraste 
mais abrangente comparado a outros aplicativos, em que os ajustes são limitados, e geralmente não suportam todos os recursos da faixa dinâmica DICOM; ajuste de espessura de corte personalizado, muitas vezes limitado e pré-definido em outras aplicações; ajuste de nitidez personalizado, muitas vezes limitado em outras aplicações; algoritmo avançado de redução de ruido que melhora a qualidade da imagem; filtros de imagem predefinidos, filtros de para análise de volume do canal radicular com a capacidade de ampliar a imagem em mais de 1000x (reconstruções em 3D) sem perda de resolução, e personalização de parâmetros de imagem automática para melhor padronização e oportunidades de pesquisa; captura com resolução da tela de 192 dpi, com uma opção de 384 dpi, em contraste com os 96 dpi das aplicações similares. Este novo software de TCFC pode apoiar as tomadas de decisões para o tratamento de casos endodônticos complexos e melhorar os resultados do diagnóstico e do tratamento. A melhoria efetiva da qualidade da imagem favorece a prescrição e a interpretação racional das imagens de TCFC.

\section{References}

1. Hounsfield GN. Computerized transverse axial scanning (tomography): Part I. Description of system. Brit J Radiol 1973;46:1016-1022.

2. Robb RA. The dynamic spatial reconstructor: an x-ray videofluoroscopic CT scanner for dynamic volume imaging of moving organs. IEEE Trans Med Imaging 1982;1:22-33.

3. Mozzo P, Procacci $C$, Taccoci A, et al. A new volumetric $C T$ machine for dental imaging based on the cone-beam technique: preliminary results. Eur Radiol 1998;8:1558-1564.

4. Arai $Y$, Tammisalo $E_{1}$ Iwai $K_{1}$ et al. Development of a compact computed tomographic apparatus for dental use. Dentomaxillofac Radiol1999;28:245-248.

5. Scarfe WC, Farman AG, Sukovic P. Clinical applications of cone-beam computed tomograghy in dental practice. J Can Dent Ass 2007;72:7580.

6. Cotton TP, Geisler TM, Holden DT, et al. Endodontic applications of cone beam volumetric tomography. J Endod 2007;33:1121-1132.

7. Patel S, Dawood A, Pitt Ford T, et al. The potential applications of cone beam computed tomography in the management of endodontic problems. Int Endod J 2007:40:818-830.

8. Bueno MR, Estrela C, Azevedo BC, et al. Cone beam computed tomography: Revolution in dentistry. Rev Ass Paul Cir Dent 2007:61:325-328.

9. Scarfe WC, Farman AG. What is cone-beam CT and how does it work? Dent Clin N Am 2008;52:707-730.

10. Kiljunen T, Kaasalainen T, Suomalainen A, et al. Dental cone beam CT: A review. Phys Med 2015;31:844-860.

11. Estrela C, Pécora JD, Estrela CRA, et al. Common operative procedural errors and clinical factors associated with root canal treatment. Braz Dent J 2017;28:1-12.

12. Miracle AC, Mukherji SK. Cone beam CT of the head and neck. Part 1: Physical Principles. Am J Neuroradiol 2009;30:1088-1095.

13. Miracle AC, Mukherji SK. Cone beam CT of the head and neck. Part 2: Clinical Applications. Am J Neuroradiol 2009;30:1285-1292.

14. Estrela $C$, Bueno MR, Leles $C R$, et al. Accuracy of cone beam computed tomography and panoramic and periapical radiography for detection of apical periodontitis. J Endod 2008;34:273-279.

15. Estrela C, Bueno MR, Alencar AHG, et al. Method to evaluate inflammatory root resorption by using cone beam computed tomography. J Endod 2009; 35:1491-1497.

16. Estrela $C$, Bueno $M R$, Azevedo $B$, Azevedo JR, Pécora JD. A new periapical index based on cone beam computed tomography. J Endod 2008;34:1325-1331.

17. Bueno MR, Estrela C, Figueiredo JAP, et al. Map-reading strategy to diagnose root perforations near metallic intracanal posts by using cone beam computed tomography. J Endod 2011;37:85-90.

18. Estrela $C$, Holland $R$, Estrela $C R$, et al. Characterization of successful root canal treatment. Braz Dent J 2014; 25:3-11.

19. Bender IB. Factors influencing the radiographic appearance of bony lesions. J Endod 1982;8:161-170.

20. Bender $\mathbf{I B}$, Seltzer $\mathrm{S}$. Roentgenographic and direct observation of experimental lesions in bone I. J Amer Dent Ass 1961;62:152-160.

21. Lofthag-Hansen $S$, Huumonen $S$, Gröndahl K, et al. Limited cone-beam $\mathrm{CT}$ and intraoral radiography for the diagnosis of periapical pathology. Oral Surg Oral Med Oral Pathol Oral Radiol Endod 2007;103:114-119.

22. Hashimoto $K$, Arai $Y$, Iwai $K$, et al. A comparison of a new limited cone beam computed tomography machine for dental use with a multidetector row helical CT machine. Oral Surg Oral Med Oral Pathol Oral Radiol Endod 2003;95:371-377.

23. Hoffmann EC. Physic parameters involved with image quality in cone beam computed tomography. Rev Grad PUCRS 2011;4:1-62.

24. Nemtoi A, Czink C, Haba D, et al. Cone beam CT: a current overview of devices. Dentomaxillofac Radiol 2013;42:20120443.

25. Guerrero ME, Jacobs R, Loubele M, et al. State-of-the-art on cone beam CT imaging for preoperative planning of implant placement. Clin Oral Investig 2006;10:1-7.

26. Ludlow JB, Timothy $R$, Walker $\mathrm{C}$, et al. Effective dose of dental CBCT-a meta analysis of published data and additional data for nine CBCT units. Dentomaxillof Radiol 2015;44:1-25.

27. Ludlow JB. A manufacturer's role in reducing the dose of cone beam computed tomography examinations: effect of beam filtration. Dentomaxillofac Radiol 2011;40:115-122.

28. Ludlow JB, Ivanovic M. Comparative dosimetry of dental CBCT devices and 64-slice CT for oral and maxillofacial radiology. Oral Surg Oral Med Oral Pathol Oral Radiol Endod 2008;106:106-114.

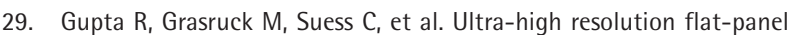
volume CT: fundamental principles, design architecture, and system characterization. Eur Radiol 2006;16:1191-1205.

30. Farman AG. Applying DICOM to dentistry. J Digit Imaging 2005:18: 23-27.

31. Pauwels R, Stamatakis H, Manousaridis G, et al. Development and applicability of a quality control phantom for dental cone-beam CT. J Appl Clin Med Phys 2011;12:3478.

32. Bamba J, Araki K, Endo A, et al. Image quality assessment of three cone beam CT machines using the SEDENTEXCT CT phantom. Dentomaxillofac Radiol 2013;42:20120445.

33. Sonya DA, Davies J, Ford NL. A comparison of cone-beam computed tomography image quality obtained in phantoms with different fields of view, voxel size, and angular rotation for i-CAT NG. J Oral Maxillofac Radiol 2016;4:31-39.

34. Bueno MR, Estrela C. Incorporation of cone beam computed tomography in dental research. In: Estrela C. Scientific methodology: Science, teaching, research. 3 ed. Artmed: Porto Alegre, RS, Brazil, 2018. p.667-684.

35. Lofthag-Hansen S, Thilander-Klang A, Ekestubbe A, et al. Calculating effective dose on a cone beam computed tomography device: 3D Accuitomo and 3D Accuitomo FPD. Dentomaxillofac Radio 2008:37:72-79.

36. Ludlow JB, Davies-Ludlow LE, Brooks SL. Dosimetry of two extraoral direct digital imaging devices: NewTom Cone Beam CT and Orthophos Plus DS panoramic unit. Dentomaxillofac Radiol 2003;32:229-234.

37. Ludlow JB, Davies-Ludlow LE, Brooks SL, et al. Dosimetry of 3 CBCT devices for oral and maxillofacial radiology: CB Mercuray, NewTom $3 \mathrm{G}$ and i-CAT. Dentomaxillof Radiol 2006;35:219-226.

38. Bueno MR. Documentation in research. In: Estrela C. Scientific methodology: Science, teaching, research. 3 ed. Artmed: Porto Alegre, RS, Brazil, 2018. p.667-684.

39. Fryback DG, Thornbury JR. The efficacy of diagnosis imaging. Med Decis Making 1991;11:88-94.

40. Pauwels R, Araki K, Siewerdsen JH, et al. Technical aspects of dental CBCT: State of the art. Dentomaxillofac Radiol 2015;44:20140224.

41. Schulze $R$, Heil $U$, Gross $D$, et al. Artefacts in CBCT: a review. Dentomaxillofac Radiol 2011;40:265-273.

42. Azevedo $B$, Lee $R$, Shintaku $W$, et al. Influence of the beam hardness on artifacts in cone-beam CT. Oral Surg Oral Med Oral Pathol Oral Radiol Endod 2008;105:e48.

43. Katsumata A, Hirukawa A, Okumura S, et al. Relationship between density variability and imaging volume size in cone-beam computerized tomography scanning of the maxillofacial region: an in vitro study. Oral Surg Oral Med Oral Pathol Oral Radiol Endod 2009;107:420-425. 
44. Decurcio DA, Bueno MR, de Alencar AH, et al. Effect of root canal filling materials on dimensions of cone-beamcomputed tomography images. J Appl Oral Sci 2012;20:260-267.

45. Estrela C, Bueno M, Silva J, et al. Effect of intracanal posts on dimensions of cone beam computed tomography images of endodontically treated teeth. Dental Press Endod 2011;1:28-36.

46. Silva DM, Campos CN, Carvalho ACP, et al. Diagnosis of mesiodistal vertical root fractures in teeth with metal posts: influence of applying filters in cone-beam computed tomography images at different resolutions. J Endod 2018;44:470-474.

47. Møller L, Wenzel A, Wegge-Larsen AM, et al. Comparison of images from digital intraoral receptors and cone beam computed tomography scanning for detection of voids in root canal fillings: An in vitro study using micro-computed tomography as validation. Oral Surg Oral Med Oral Pathol Oral Radiol 2013;115:810-818.

48. Fox A, Basrani B, Kishen A, et al. A novel method for characterizing beam hardening artifacts in cone-beam computed tomographic images. J Endod 2018;44:869-874.

49. Celikten B, Jacobs R, Vasconcelos KF, et al. Assessment of volumetric distortion artifact in filled root canals using different cone beam computed tomographic devices. J Endod 2017;43:1517-1521.

50. Vasconcelos KF, Nicolielo LF, Nascimento MC, et al. Artefact expression associated with several cone-beam computed tomographic machines when imaging root filled teeth. Int Endod J 2015;48:994-1000.

51. de Rezende Barbosa GL, Sousa Melo SL, Alencar PN, et al. Performance of na artefact reduction algorithm in the diagnosis of in vitro vertical root fracture in four different root filling conditions on CBCT images. Int Endod J 2016;49:500-508.

52. Neves FS, Freitas DQ, Campos PS, et al. Evaluation of cone-beam computed tomography in the diagnosis of vertical root fractures: the influence of imaging modes and root canal materials. J Endod 2014;40:1530-1536.

53. Oliveira MVL, Santos AC, Paulo G, et al. Application of a newly developed software program for image quality assessment in cone beam computed tomography. Imaging Sci Dent 2017;47:75-86.

54. Gambarini G, Ropini P, Piasecki $L$, et al. A preliminar assessment of a new dedicated endodontic software for use with $C B C T$ images to evaluate the canal complexity of mandibular molars. Int Endod J 2018;51:259-268.

55. AAE and AAOMR joint position statement: Use of cone beam computed tomography in endodontics. 2015/2016 Update. Chicago: American Association of Endodontists; 2015.

56. Patel S, Durack C, Abella F, et al. European Society of Endodontology position statement: the use of CBCT in endodontics. Int Endod J 2014;47:502-504.

57. SEDENTEXCT Radiation protection no.172: cone beam CT for dental and maxillofacial radiology (evidence-based guidelines). Available at: http://www.sedentexct.eu/files/radiation_protection_172.pdf. Accessed July 20, 2018.

58. Horner K, Islam M, Flygare L, et al. Consensus guidelines of the European Academy of Dental and Maxillofacial Radiology. Dentomaxillofac Radiol 2009;38:187-195.

59. Farman AG. ALARA still applies. Oral Surg Oral Med Oral Pathol Oral Radiol Endod 2005;100:395-397.

60. Estrela C, Couto GS, Bueno MR, Bueno KG, Estrela LRA, Porto OCL, Diogenes A. Apical foramen position in relation to proximal root surfaces of human permanent teeth determined by using a new conebeam computed tomographic software. J Endod 2018;44:1741-1748.

Received August 28, 2018

Accepted October 11, 2018 